\title{
HUBUNGAN KEHAMILAN IBU DI USIA MUDA DENGAN PERKEMBANGAN EMOSI ANAK USIA 3-5 TAHUN DI WILAYAH KERJA PUSKESMAS IBRAHIM ADJIE KOTA BANDUNG
}

\author{
Sri Hennyati Amiruddin \\ srihennyati@gmail.com \\ Program Studi Diploma Tiga Kebidanan STIKes Dharma Husada Bandung
}

\begin{abstract}
ABSTRAK
Masa anak-anak berlangsung dari usia 3-6 tahun, pada masa ini menurut Osborn, White, dan Bloom bahwa perkembangan kognitif anak telah mencapai 50\% ketika anak berusia 4 tahun, $80 \%$ ketika anak berusia 8 tahun, dan genap 100\% ketika anak berusia 18 tahun. Pertumbuhan dan perkembangan mengalami peningkatan yang pesat pada usia dini, yaitu dari 0 sampai 5 tahun. Masa ini sering juga disebut sebagai fase "Golden Age". Golden age merupakan masa yang sangat penting untuk memperhatikan tumbuh kembang anak secara cermat agar sedini mungkin dapat terdeteksi apabila terjadi kelainan. Tujuan Penelitian adalah untuk mengetahui hubungan kehamilan ibu di usia muda dengan perkembangan emosi anak usia 3-5 tahun di wilayah kerja Puskesmas Ibrahim Adjie Kota Bandung Tahun 2019. Penelitian ini merupakan penelitian observational dengan desain kohort historikal dengan tekink pueposive sampling. Penelitian ini melihat hubunagna kehamilan ibu di usia muda dengan perkembangan emosia nanak usia 3-5 tahun di wilayah kerja puskesmas Ibrahim Adjie Kota Bandung. Sampel dengan jumlah sampel 74 responden. Variabel Independen yaitu perkembangan emosi anak diukur menggunkan kuesioner SDQ. Variabel dependen yaitu usia ibu diukur menggunakan kuesioner. Variabel luar yaitu jumlah anak, jenis kelamin, pendidikan ibu ayah, pola asuh, dan pendapatan diukur menggunakan kuesioner. Analisis yang digunakan yaitu chi square dan multipel regresi logistik. Hasil menunjukan bahwa terdapat hubungan kehamilan di usia muda dengan perkembangan emosi anak usia 3-5 tahun. Anak usia 3-5 tahun yang lahir dari ibu yang hamil di usiamu dan mempunyai peluang $80 \%$ mengalami gangguan perkembangan emosi disbanding ibu usia dewasa. Saran agar remaja, keluarga, dan tenaga kesehatan memperhatikan usia ketika hamil supaya dapat menghindari gangguan emosi anak usia 3-5 tahun dengan membuat program hamil di usai 20- 35 tahun.
\end{abstract}

Kata kunci : Anak usia 3-5 tahun, Kehamilan, Perkembangan emosi anak, Usia Ibu Muda

\section{PENDAHULUAN}

Masa anak-anak berlangsung dari usia 36 tahun, pada masa ini menurut Osborn, White, dan Bloom bahwa perkembangan kognitif anak telah mencapai 50\% ketika anak berusia 4 tahun, $80 \%$ ketika anak berusia 8 tahun, dan genap 100\% ketika anak berusia 18 tahun. Pertumbuhan dan perkembangan mengalami peningkatan yang pesat pada usia dini, yaitu dari 0 sampai 5 tahun. Masa ini sering juga disebut sebagai fase "Golden Age". Golden age merupakan masa yang sangat penting untuk memperhatikan tumbuh kembang anak secara cermat agar sedini mungkin dapat terdeteksi apabila terjadi kelainan. Anak usia 3-5 tahun berada dalam masa pra sekolah pada 
masa ini anak sedang mengalami perkembangan m,otorik yang pesat.

Perkembangan kemampuan berbahasa, kreativitas, kesadaran sosial, kesadaran emosional, dan inteligensia berjalan sangat cepat. ${ }^{5}$ Masalah perkembangan yang dapat terjadi pada anak usia pra sekolah adalah masalah mental. Menurut penelitian Davien dan Teifion,di Amerika terdapat 20\% anak yang datang ke dokter umum dengan gangguan psikologis yang biasanya bersumber dari keluhan fisik, dan $30 \%$ anak yang datang ke klinik dokter spesialis anak dengan gangguan psikiatri, penelitian yang pernah dilakukan di Jombang didapatkan prevalensi gangguan mental emosional pada anak usia 3-5 tahun sebanyak 74,2\%. ${ }^{6}$ Prevalensi gangguan emosional dan perilaku pada anak usia prasekolah cukup tinggi yaitu 34,10\% (Pahl et al, 2010). Sekitar 9,5\% sampai $14,2 \%$ anak usia 3-5 tahun yang memiliki masalah sosial emosional akan berdampak negatif terhadap perkembangan dan kesiapan sekolahnya. ${ }^{7}$

Anak yang mengalami terlalu banyak emosi kurang baik dan sedikit mengalami emosi-emosi yang menyenangkan hal ini akan mengganggu pandangan hidup dan mendorong perkembangan watak yang kurang baik. Anak akan lebih cepat mendapat ekspresi wajah yang kelihatan masam, cemberut atau tidak senang. Bahaya yang juga besar terhadap penyesuaian pribadi dan sosial (Hurlock,2013).

Anak usia 3-6 tahun perlu untuk mengatur emosi pada dirinya dalam rangka mempertahankan interaksi sosial yang baik.
Pengukuran emosi anak dapat dilakukan menggunakan Strengths and Difficulties Questionnaire (SDQ). SDQ adalah sebuah instrumen skrining perilaku singkat untuk anak dan remaja (3-17 tahun) yang memberikan gambaran singkat dari perilaku yang berfokus pada kekuatan dan juga kesulitan mereka (Black, Pulford, Christie, \& Wheeler, 2010). Perkembangan emosi anak dipengaruhi beberapa faktor meliputi umur, jenis kelamin, genetik, keluarga, hormon, psikologi ibu ketika hamil, gizi ibu, pola asuh, sosio-ekonomi, pendidikan ibu, stimulasi dan lain-lain . ${ }^{9}$ Salah satu faktor yang memengaruhi perkembangan emosi anak yaitu usia ibu ketika hamil. Kehamilan di usia muda adalah kehamilan yang terjadi pada wanita berusia $<20$ tahun.

Wanita usia muda mengalami proses pematangan fisik lebih cepat daripada pematangan psikososialnya. Oleh karena itu, seringkali terjadi ketidakseimbangan emosi sehingga sangat sensitif maupun rawan terhadap stress. Hal tersebut merugikan kesehatan, pertumbuhan, dan perkembangan janin karena belum matangnya alat reproduksi untuk hamil apalagi bila ditambah dengan tekanan (stress) psikologi, sosial, dan ekonomi (Manuaba, 2010).

\section{METODE PENELITIAN}

Jenis penelitian ini observational dengan desain kohort historikal. Kohort historikal merupakan suatu penelitian dimana subyek diamati dalam kurun waktu tertentu terhadap faktor risiko kemudian dinilai efek yang telah 
terjadi. Pada penelitian ini peneliti melihat hubungan kehamilan ibu di usia muda dengan perkembangan emosi anak usia 3-5 tahun di wilayah Kerja Puskesmas Ibrahim Adjie Kota Bandung. Teknik pengambilan sampel yang digunakan pada penelitian ini adalah purposive sampling yang merupakan jenis dari non probability sampling yaitu memilih responden dengan pertimbangan subjektif dan praktis, bahwa responden tersebut dapat memberikan informasi yang memadai untuk menjawab pertanyaan penelitian. ${ }^{31}$ Jumlah sampel pada penelitian ini 74 responden, dan memenuhi kriteris inklusi dan ekslusif, adapun kriteria insklusi adalah: ibu hamil pada tahun 20182019 yang anaknya masih hidup dan tinggal di wilayah kerja puskesmas Ibrahim Adjie.

\section{HASIL PENELITIAN}

Tabel 1 Distribusi Frekuensi dan Homogenitas Subyek

\begin{tabular}{|c|c|c|c|c|c|}
\hline \multirow[t]{2}{*}{ Karakteristik } & \multicolumn{2}{|c|}{$\begin{array}{l}\text { Hamil di Usia Muda } \\
\quad(<20 \text { tahun })\end{array}$} & \multicolumn{2}{|c|}{$\begin{array}{l}\text { Hamil di Usia Dewasa } \\
\text { (usia 20-35 tahun) }\end{array}$} & \multirow[t]{2}{*}{ p-value } \\
\hline & $\mathbf{N}$ & $\%$ & $\mathbf{N}$ & $\%$ & \\
\hline \multicolumn{6}{|l|}{ Pola Asuh } \\
\hline Negatif & 4 & $10,8 \%$ & 1 & $2,7 \%$ & 0,358 \\
\hline Positif & 33 & $89,2 \%$ & 36 & $97,3 \%$ & \\
\hline \multicolumn{6}{|l|}{ Jumlah anak } \\
\hline Anak $>1$ & 12 & $32,4 \%$ & 28 & $75,7 \%$ & 0,000 \\
\hline Anak 1 & 25 & $67,6 \%$ & 9 & $24,3 \%$ & \\
\hline \multicolumn{6}{|l|}{ Jenis Kelamin } \\
\hline Laki-laki & 18 & $48,6 \%$ & 15 & $40,5 \%$ & 0,640 \\
\hline Perempuan & 19 & $51,4 \%$ & 22 & $59,5 \%$ & \\
\hline \multicolumn{6}{|l|}{ Pendidikan Ibu } \\
\hline Rendah & 9 & $24,3 \%$ & 8 & $21,6 \%$ & 1,000 \\
\hline Tinggi & 28 & $75,7 \%$ & 29 & $78,4 \%$ & \\
\hline \multicolumn{6}{|l|}{ Pendidikan Ayah } \\
\hline Rendah & 13 & $35,1 \%$ & 13 & $35,1 \%$ & 1,000 \\
\hline Tinggi & 24 & $64,9 \%$ & 24 & $64,9 \%$ & \\
\hline \multicolumn{6}{|l|}{ Pendapatan Orang Tua } \\
\hline Pendapatan $<$ UMR & 18 & $48,6 \%$ & 18 & $48,6 \%$ & 1,000 \\
\hline Pendapatan $\geq$ UMR & 19 & $51,4 \%$ & 19 & $51,4 \%$ & \\
\hline
\end{tabular}

Tabel 1 memperlihatkan karakteristik responden kelompok ibu hamil di usia muda memiliki pola asuh positif sejumlah 33 orang $(89,2 \%)$, jumlah anak 1 ada 25 orang $(67,6 \%)$, jenis kelamin anak yang dimiliki responden hampir sama rata yaitu perempuan sejumlah 19 anak $(51,4 \%)$ dan laki-laki 18 anak $(48,6 \%)$. Pendidikan ibu sebagian besar tinggi (SMA-PT) sejumlan 28 orang $(75,7 \%)$, sedangkan pendidikan ayah antara yang rendah dan tinggi seimbang yaitu $35,1 \%$, pendapatan hampir sama rata yaitu < Rp 1.404 .760 
Tabel 2 Hubungan Kehamilan ibu di usia muda dengan Perkembangan Emosi Anak usia 3-5 tahun

\begin{tabular}{|c|c|c|c|c|c|}
\hline \multirow{2}{*}{$\begin{array}{l}\text { Variabel Kehamilan ibu } \\
\text { di usia muda }\end{array}$} & \multicolumn{2}{|c|}{$\begin{array}{c}\text { Perkembangan Emosi Anak } \\
\text { usia 3 } 5 \text { tahun }\end{array}$} & \multirow[t]{2}{*}{$p$-value } & \multirow[t]{2}{*}{$\mathbf{R R}$} & \multirow[t]{2}{*}{ CI } \\
\hline & Tidak Normal & Normal & & & \\
\hline Ya (usia <20) & 10 & 27 & \multirow{2}{*}{0,067} & \multirow{2}{*}{3,33} & \multirow{2}{*}{$0,997-11,145$} \\
\hline Tidak (usia 20-35 tahun) & 3 & 34 & & & \\
\hline
\end{tabular}

Tabel 2 menunjukan bahwa ibu hamil di usia muda yang mengalami masalah pada perkembangan emosi anak usia 3-5 tahun sejumlah 10 orang $(76,9 \%)$, sedangkan usia dewasa sejumlah 3 orang $(23 \%)$ dari total responden 74 orang. Hasil uji chi-square menunjukan nilai p-value $0,067 \mathrm{RR}=3,33$ (95\% CI 0,997-11,145). Anak usia 3-5 tahun yang dilahirkan ketika ibu hamil di usia muda memiliki risiko 3,33 kali mengalami gangguan perkembangan emosi dibanding ibu yang hamil di usia dewasa.

Tabel 3. Uji Hubungan Berbagai Faktor dengan Perkembangan emosi anak usia 3-5 tahun secara bersama-sama

\begin{tabular}{lrccc}
\hline Variabel & B & p-value & RR & CI (95\%) \\
\hline Usia & 1,614 & 0,031 & 5,021 & $1,157-21,795$ \\
\hline Pendapatan & 2,210 & 0,008 & 9,120 & $1,767-47,070$ \\
\hline
\end{tabular}

Tabel 3 menunjukan faktor yang memengaruhi gangguan perkembangan emosi anak usia 3-5 tahun dari variabel yang diteliti adalah usia dan pendapatan. Hasil tersebut menunjukan bahwa usia ibu ketika hamil memiliki hubungan dengan p-value $0,031 \mathrm{RR}=5,021(95 \% \mathrm{CI}$ 1,157 - 21,795). Anak usia 3-5 tahun yang dilahirkan dari kehamilan ibu di usia muda memiliki risiko 5 kali mengalami gangguan perkembangan emosi anak dibanding ibu yang hamil di usia dewasa. Selain itu, pendapatan juga memiliki hubungan yang bermakna $p$ value 0,008 dengan $\mathrm{RR}=2,210(95 \%$ CI 1,767 -47,070). Anak usia 3-5 tahun yang dilahirkan dari orangtua dengan pendapatan $<\mathrm{Rp}$ 1.404.760 berisisko 9 kali mengalami gangguan perkembangan emosi anak dibanding pendapatan $\geq$ Rp 1.404.760.

Faktor-faktor yang memengaruhi perkembangan yang diikutkan dalam penelitian ini adalah usia, pola asuh, jumlah anak, jenis kelamin, pendidikan ibu, pendidikan ayah, dan pendapatan. Faktor usia ketika hamil dapat memengaruhi kondisi psikologis untuk menjadi seorang ibu. Hal tersebut dapat memengaruhi perkembangan anak yang akan dilahirkan. Tekanan ibu ketika hamil memengaruhi anak yang sedang berkembang 
baik sebelum maupun sesudah kelahiran.

Tekanan ibu ketika hamil memengaruhi anak yang sedang berkembang baik sebelum maupun sesudah kelahiran. ${ }^{15}$ Apabila tekanan emosi berlangsung lama akan memengaruhi keseimbangan endokrin, maka kegelisahan akan terus terbawa sampai periode pascanatal dan sangat memengaruhi penyesuaian diri pada perkembangan anaknya. ${ }^{15}$

Usia ibu dapat memengaruhi kondisi psikologi atau kesiapan mental ketika hamil hingga melahirkan dan mendidik anak. Hal tersebut sesuai penelitian Sucipto yang berjudul "Hubungan antara Usia Ibu Hamil dengan Kesiapan Mental Menghadapi Persalinan di Desa Kalisidi, Kecamatan Ungaran Barat" yang menunjukan bahwa ada hubungan antara usia ibu hamil dengan kesiapan mental dalam menghadapi persalinan yang ditinjau dari tingkat kecemasan ibu nilai $p$ value 0,006. Selain itu, ibu yang hamil di usia muda dapat berpengaruh pada kondisi psikologinya.

Psikologi dapat memengaruhi produksi ASI sesuai penelitian Nurul Kamariyah yang berjudul "Kondisi Psikologi Mempengaruhi Produksi Asi Ibu Menyusui Di BPS Aski Pakis Sido Kumpul Surabaya" menunjukan bahwa ada hubungan antara kondisi psikologis ibu dengan kelancaran produksi ASI $p$ value 0,001. Berdasarkan penelitian Any Setyarini, dkk yang berjudul "Pengaruh pemberian ASI eksklusif dan non eksklusif terhadap mental emosional anak usia 3-4 tahun" menunjukan bahwa ada hubungan riwayat pemberian ASI $(\mathrm{p}=0,001)$ terhadap masalah mental Jurnal Penelitian Kesehatan STIKes Dharma Husada Bandung emosional anak.

\section{KESIMPULAN}

Bersasarkan hasil penelitian yang telah dilakukan maka dapat disimpulkan bahwa terdapat hubungan yang bermakna antara pendapatan dengan perkembangan emosi anak, $p$ value $0,008 \mathrm{RR}=9,120(95 \%$ CI 1,767 47,070). Ada hubungan yang bermakna antara usia ibu ketika hamil dengan gangguan perkembangan emosi anak usia 3-5 tahun dengan $p$ value 0,031 (95\% CI 1,157 21,795). Faktor yang paling memengaruhi gangguan perkembangan emosi anak usia 3-5 tahun adalah pendapatan dan usia ibu ketika hamil.

\section{DAFTAR PUSTAKA}

1. Maylan, Wulandari. Hubungan status gizi dengan perkembangan motorik kasur dan motorik halus anak usia 3-5 tahun di p;ay group Traju Mas. Purworejo. 2010.

2. Wong, Donna L (2008).Buku Ajar Keperawatan Pedeatrik Wong.Edisi 6.Jakarta: EGC

3. Dinda A. (2013). Pengetahuan Ibu tentang Stimulasi Perkembangan dengan Tingkat Perkembangan Motorik Halus Pada Masa Prasekolah (3-6 Tahun) Brawijaya.

4. Schwartz, M., W. (2011). Pedoman Klinis Pediatri. Jakarta: EGC.

5. Delaune dan Ladner. (2011). Fundamental Of Nursing Standard And Practice.FourthEdition. Cengage 
Learning. Delmar.

6. Maramis W.F. (2013). Catatan Ilmu Kedokteran Jiwa. Surabaya: Airlangga University Press.

7. Kemenkes RI. (2010). Pedoman Pelaksanaan Stimulasi Deteksi IntervensiTumbuhKembang di Tingkat Pelayanan Kesehatan Dasar. Jakarta.

8. Brauner, C.B. \& Stephens, B.C. (2006). Estimating the Prevalence of EarlyChildhoodSerious

Emotional/Behavioral

Disorder:

Challenges

and

Recommendations.PublicHealth Reports 121: 303-310.

9. Arikunto. (2006). Prosedur Penelitian Suatu Pendekatan Praktek. Jakarta : PT.RinekaCipta.

10. Arvin, Behrman. (2000). Ilmu Kesehatan Anak. Jakarta: EGC.

11. Black, S., Pulford, J., Christie, G., \& Wheeler, A. (2010). Differences in New Zealand School Student's reported Strenght and Difficulties. New Zealand Journal of Psychology, 39(9).

12. Asti, Melani \&Rika Yustita. (2010).Hubungan Pola Asuh Orang

Tua Dengan Perkembangan Emosi Anak Usia PraSekolah di TK Rokhmatul Magfiroh Desa Pakis aji Kecamatan pakis aji Kabupaten Malang http://jurnal.unimus.ac.id/index.php/FIKk eS/article/view/761 diakses tanggal 13 Januari 2017.

13. Santrock, John W. (2012) .Life-span Jurnal Penelitian Kesehatan STIKes Dharma Husada Bandung
Development : Perkembangan Masa Hidup. Edisi 5 jilid 2, Jakarta : Erlangga.

14. Hurlock, E. B. (2013). Perkembangan Anak Jilid 1 Edisi 6. Jakarta: Erlangga.

15. Goodman. (2001) Dasar-dasar Farmakologi Terapi, Edisi 10, 700-713, Jakarta, EGC.

16. Dahlan,Sopiyudin.(2010). Besar Sampel dan Cara Pengambilan Sampel dalamPenelitian Kedokteran dan Kesehatan".Jakarta: Salemba Medika.

17. Soetjiningsih. (2014). Tumbuh Kembang Anak Edisi ke-2. Jakarta : EGC.

18. Manuaba,IBG. (2010). Ilmu Kebidanan, penyakit Kandungan dan KB untukPendidikan Bidan Edisi 2. Jakarta:EGC.

19. Ruswana. (2006) . Ibu Hamil Resiko Tinggi. Tersedia dalam : http://medicastore.com/penyakit/569/Keh amilan_Resiko_Tinggi.htmldiaks es tanggal 15 Januari 2017.

20. Maryunani,Anik. (2010).Ilmu Kesehatan Anak Dalam Kebidanan. Jakarta: CV. TransInfo Media.

21. Masland, P.R. (2004). Apa yang ingin diketahui remaja tentang seks. Jakarta: Bumi Aksara.

22. Gunawan G, Fadlyana E, Rusmil K. (2011). Hubungan Status Gizi dan Perkembangan AnakUsia 1-2 Tahun. Sari Pediatri.

23. Tanuwijaya. Suganda. (2008). Tumbuh Kembang Anak dan Remaja. Jakarta: CV. Sagung Seto. 
24. Christiari AY, Syamlan R, Kusuma F. (2013).Pengetahuan Ibu tentang Stimulasi DinidenganPerkembangan Motorik pada Anak Usia 6-24 bulan di Kecamatan Mayang Kabupaten Jember. Pustaka Kesehatan.

25. Astuti, H., 2005, Psikologi perkembangan masa dewasa, Surabaya: Usaha.

26. Suharto, Edi. (2005), Membangun Masyarakat Memberdayakan Rakyat, Bandung.

27. Budiarto, Eko. (2012). Biostatistik untuk Kedokteran dan Kesehatan Masyarakat.Jakarta : EGC.

28. Sugiyono. (2012). Memahami Penelitian Kualitatif. Bandung : LFABETA.

29. Damayanti. (2011). Metode Penelitian Pendidikan Bahasa. Bandung: Remaja Rosdakarya.

30. Kamariyah, Nurul. 2014. Kondisi Psikologi Mempengaruhi Produksi Asi Ibu Menyusui Di BPS Aski Pakis Sido Kumpul Surabaya. Jurnal Ilmiah Kesehatan, Vol 7, No 12, Pebruari 2014., hal 29-36 diambil dari http://journal.unusa.ac.id/index.php/jhs/art icle/view/50 diakses tanggal 3 Maret 2017
31. Martani, Wisjnu. 2012. "Metode Simulasi dan Perkembangan Anak Usia Dini”. Jurnal Psikologi. 39 (1).

32. Sulistyoningsih, Hariani. (2011). Gizi untuk Kesehatan Ibu dan Anak. Yogyakarta : Graha Ilmu.

33. Sucipto, Sintikhewati, dan Sakundarno Adi. 2010. Hubungan antara Usia Ibu Hamil dengan Kesiapan Mental Menghadapi Persalinan di Desa Kalisidi, Kecamatan Ungaran Barat. Jurnal Kebidanan Panti Wilasa, Vol. 1 No. 1 diambil dari http://ejurnal.akbidpantiwilasa.ac.id/index .php/kebidanan/\%20article/view File/6/5 diakses tanggal 2 Juli 2017

34. Dinas Kesehatan Kabupaten Bantul. (2016). Profil Kesehatan Kabupaten Bantul. 2016. Yogyakarta: Dinas Kesehatan Kabupaten Bantul.

35. Dinas Kesehatan Provinsi DIY. (2015). Profil Kesehatan Yogyakarta 2015.Yogyakarta: Dinas Kesehatan Yogyakarta. 